\title{
Article \\ The effect of technological parameters of PMMA thermoplastic welding in the hot air stream on the quality of joints
}

\author{
Damian Przewodowski ${ }^{1}$, Dariusz Golański ${ }^{1}$ ** \\ ${ }^{1}$ Warsaw University of Technology, Poland \\ Damian Przewodowski, M.Sc.; damianprzewodowski@wp.pl; \\ * Correspondence: Prof. Dariusz Golański; dgol@wip.pw.edu.pl
}

Received: 30.04.2019; Accepted: 29.07.2019

\begin{abstract}
The work covers the welding of thermoplastic polymethyl methacrylate (PMMA) and concerns the assessment of the impact of the main welding parameters on joint strength. The strength test of welded joints made of thermoplastic material was carried out. The aim of the study was to determine the influence of the main technological parameters of welding, such as: temperature and welding speed, gas stream output, filler rod pressure, diameter and type of hot air gun nozzle on the strength of the obtained joint. The method of sample preparation and testing was performed in accordance with the guidelines of PN-EN 12814-2: 2002 "Tests of welded joints in semi-finished products made of thermoplastics - Part 2: Tensile test". Visual evaluation of welded samples and analysis of results obtained from the tensile test made it possible to draw conclusions about the influence of selected welding parameters on joint strength. The decisive influence on the strength of joints was caused by welding defects, in the form of lack of side wall fusion and porosity.
\end{abstract}

Keywords: welding PMMA plastic; tensile strength; welding parameters

\section{Introduction}

Plastics (polymers) are currently used in almost all sectors of the economy and in everyday life. They are used in household appliances, automotive, medicine, textile, aviation, machine, chemical, armament, agriculture, electronics, construction and many others [1,2]. In the world, ready-made products or semifinished products made of polymers of various shapes and dimensions are increasingly being used in place of construction materials (e.g. metals, wood, glass, stone). They are used as basic or special materials due to their physical and chemical properties. A large number of polymeric materials or plastics are currently known. No other material group known can achieve such a variety of types. They are characterized by a very wide range of properties, and each year a new range of polymers and plastics obtained from them is introduced to the market or existing ones are improved [3]. The production of polymers and additives is one of the best developing industries in the chemical industry. Polymer materials are used so often because of their advantages such as low specific gravity, high resistance to chemical agents, ease of processing and dyeing, the possibility of obtaining transparent products, aesthetic appearance, corrosion resistance, low processing temperature, possibility of multiple processing (recycling) etc. [4]. Compared to metals, polymeric materials are characterized by much lower strength (tensile strength of PMMA material reaches $75 \mathrm{MPa}$ )

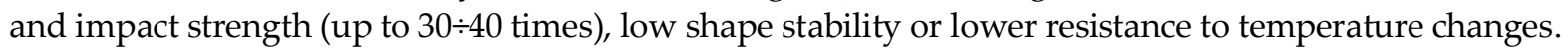

The development of plastics resulted in the necessity of joining them, which contributed to the development of new welding and joining techniques. Easy access to plastics contributed to the development of methods and devices with more precise control systems, a higher degree of automation and better control for their processing. It is possible to both cut and join elements made of plastics, e.g. by welding, gluing or laminating [5].

Products made of polymers may be damaged during use. Some plastic products may be regenerated [6]. Welding [7] can be one of the repair methods, i.e. the permanent connection of these products. Welding of plastics requires appropriate experience to prevent failure to maintain important process variables, such as overheating of the welding site, improper preparation of welded edges, or welding of two different types of plastics, which may lead to unsatisfactory quality of the joint $[8,9]$.

It should be remembered that correctly carried out the process of welding plastics does not give complete assurance of obtaining a certain level of quality of the welded joint, guaranteeing its strength 
ensuring load transfer. Assessment of the welding process in terms of the required level of joint quality requires knowledge of the phenomena associated with the formation of the joint (softening of the plastic, diffusion of macromolecules, heat transport, formation of flashes). The analysis of this information makes it easier to predict the quality and expected properties of the welded joint, and also helps to control the welding process. Quick adjustment of process parameters is possible if irregularities in the welding process are detected [10,11]. The purpose of this work was to investigate the effect of selected technological parameters of the welding process of thermoplastics PMMA (polymethyl methacrylate) in the hot gas (air) stream on the quality of joints obtained.

\section{Subject of the research}

Samples for welding in the hot air stream were made of PMMA (polymethyl methacrylate). This material is produced in the form of plates, blocks, rods and pipes. It is used for aviation and car windows, lenses, headlights, household items, machine components. Polymethyl methacrylate is a thermoplastic material, naturally transparent. It can be easily dyed any color and with different light transmittance. PMMA is resistant to weather conditions, low temperature, grease, oil and water. It burns slowly with a yellow and blue glowing flame [12]. The main properties of PMMA are listed in table I.

Table I. Selected properties of polymethyl methacrylate (PMMA) [13]

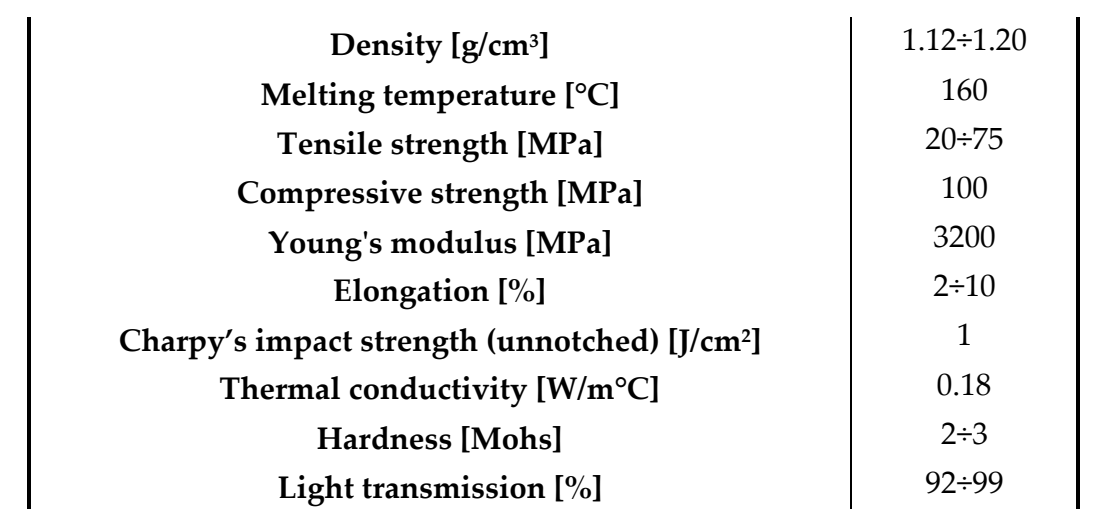

\section{Test stand}

Welding of PMMA samples was carried out manually in a stream of hot air using a Technet 858D welding machine with a power of $700 \mathrm{~W}$. The welding machine enables smooth temperature control in the range from 100 to $450{ }^{\circ} \mathrm{C}$. The temperature is controlled by a sensor located at the hot air gun's outlet. The hot air flow can be adjusted to $120 \mathrm{l} / \mathrm{min}$. The device has replaceable round welding nozzles with diameters of 3, 5, $7 \mathrm{~mm}$, flat $9 \mathrm{~mm}$ and square $10 \times 10 \mathrm{~mm}$.

The MTS Bionix strength testing machine, model 370.02, was used for the tensile test of the obtained welded joints. Joint tension was carried out at a speed of $1 \mathrm{~mm} / \mathrm{min}$, automatically recording the change in force and the extension of the sample.

As part of the planned tests, welded joints of prepared samples made of PMMA were made. Samples were welded with the following variable parameters: air temperature, welding speed, pressure, gas flow, nozzle diameter and nozzle shape. The same type and dimensions of the filler rod and constant distance between the hot air gun and the surface of the samples were used in all samples. The list and designation of parameters and welding samples are given in table II. The initial welding parameters were selected on the basis of preliminary tests: temperature $350{ }^{\circ} \mathrm{C}$, speed $30 \mathrm{~mm} / \mathrm{min}$, pressure $10 \mathrm{~N}$, gas flow $40 \mathrm{l} / \mathrm{min}$, using a nozzle with a diameter of $5 \mathrm{~mm}$. In addition to these parameters, the study also used increased and reduced values compared to those initially adopted.

After the welding process, a visual assessment of the quality of the weld was carried out by determining the occurrence of such incompatibilities as weld unevenness, sticking and lack of penetration, incomplete penetration, lack of welding groove fill, too high weld, visible porosity, stains, streaks, discoloration, charring occurring in the weld and in the heat affected zone (HAZ), lack of continuity of the weld, cracks, no leakage, differences in the mutual position of the welded elements in relation to the solid welded sample. Visual tests were carried out in accordance with the guidelines of the Office of Technical Inspection No. UDT-ST-1/00. 
Table II. Welding parameters for the tested PMMA samples ${ }^{*}-$ the same sample - standard)

\begin{tabular}{|c|c|c|c|c|c|}
\hline Sample & $\begin{array}{c}\text { Temperature } \\
{\left[{ }^{\circ} \mathrm{C}\right]} \\
\end{array}$ & $\begin{array}{c}\text { Welding speed } \\
{[\mathrm{mm} / \mathrm{min}]}\end{array}$ & $\begin{array}{c}\text { Downforce } \\
\text { [N] }\end{array}$ & $\begin{array}{c}\text { Gas flow } \\
{[1 / \mathrm{min}]}\end{array}$ & $\begin{array}{c}\text { Nozzle shape } \\
{[\mathrm{mm}]}\end{array}$ \\
\hline \multicolumn{6}{|c|}{ Temperature effect } \\
\hline $\mathrm{T} 1$ & 330 & & & & \\
\hline $\mathrm{T} 2^{*}$ & 350 & 30 & 10 & 40 & round $\varnothing 5$ \\
\hline $\mathrm{T} 3$ & 370 & & & & \\
\hline \multicolumn{6}{|c|}{ Speed effect } \\
\hline V1 & & 15 & & & \\
\hline $\mathrm{V} 2^{*}$ & 350 & 30 & 10 & 40 & round $ø 5$ \\
\hline V3 & & 60 & & & \\
\hline \multicolumn{6}{|c|}{ Filler rod downforce effect } \\
\hline P1 & & & 5 & & \\
\hline $\mathrm{P} 2^{*}$ & 350 & 30 & 10 & 40 & round $ø 5$ \\
\hline P3 & & & 15 & & \\
\hline \multicolumn{6}{|c|}{ Gas flow effect } \\
\hline Q1 & & & & 20 & \\
\hline $\mathrm{Q}^{*}$ & 350 & 30 & 10 & 40 & round $\varnothing 5$ \\
\hline Q3 & & & & 60 & \\
\hline \multicolumn{6}{|c|}{ Nozzle diameter effect } \\
\hline D1 & & & & & round $\varnothing 7$ \\
\hline $\mathrm{D} 2^{*}$ & 350 & 30 & 10 & 40 & round $\varnothing 5$ \\
\hline D3 & & & & & round $\varnothing 3$ \\
\hline \multicolumn{6}{|c|}{ Nozzle shape effect } \\
\hline $\mathrm{K} 1^{*}$ & & & & & round ø5 \\
\hline K2 & 350 & 30 & 10 & 40 & flat $9 \times 2$ \\
\hline K3 & & & & & square $10 \times 10$ \\
\hline
\end{tabular}

\section{Samples for testing}

The test samples were made of transparent $4 \mathrm{~mm}$ thick PMMA. Type 1 fitting (Fig. 1) for flat joints was selected for strength tests in accordance with PN-EN 12814-2: 2002 (Tests of welded joints in thermoplastic semi-finished products - Part 2: Tensile test). The dimensions of the welding samples are given in table III.

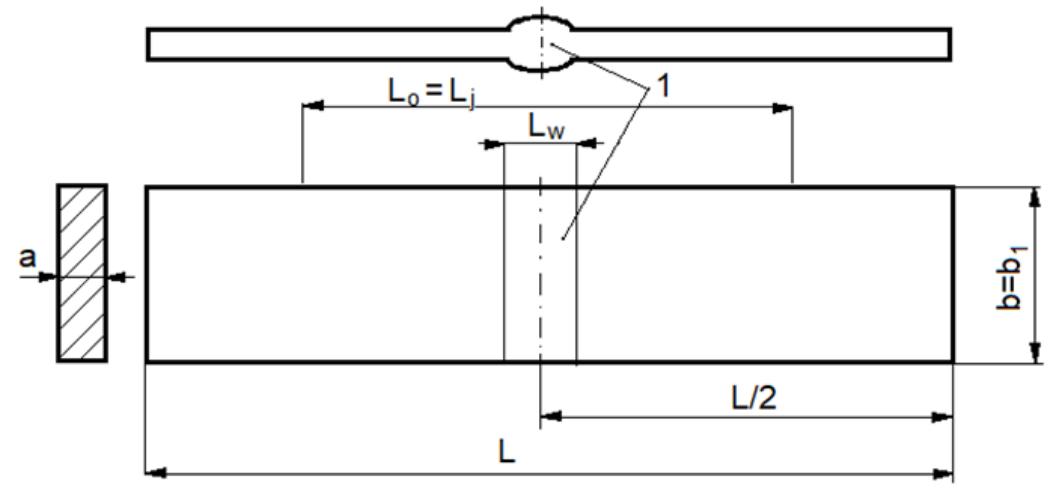

Fig. 1. Type 1 tensile specimen for flat joints: 1 - weld, a - thickness, $b$ - width, Lo - gauge length, $L_{w}$ - the largest width of the excess weld metal, $\mathrm{L}$ - total length

Table III. Dimensions of type 1 tensile specimens for flat joints according to PN-EN 12814-2:2002

\begin{tabular}{cccc}
\hline $\mathbf{a}[\mathbf{m m}]$ & $\mathbf{b}[\mathbf{m m}]$ & Lo $[\mathbf{m m}]$ & $\mathbf{L}[\mathbf{m m}]$ \\
\hline $\mathrm{a} \leq 10$ & 15 & 120 & $\geq 170$ \\
$10<\mathrm{a} \leq 20$ & 30 & 120 & $\geq 300$ \\
$\mathrm{a}>20$ & $1,5 \mathrm{a}$ & 200 & $\geq 400$ \\
\hline
\end{tabular}


The permissible deviation for the " $\mathrm{b}$ " value is $\pm 1 \mathrm{~mm}$, and for the "Lo" value it should be $\pm 2 \mathrm{~mm}$. The welding groove for the planned tensile test was chamfered on " $\mathrm{X}$ " (weld $\mathrm{X}$ ), according to the dimensions given in figure 2. For welding the prepared samples, a welding wire made of orange-colored transparent PMMA with a tensile strength of $25 \mathrm{MPa}$ was used. The filler rod has a cross-section of an isosceles triangle with $3.5 \times 2.3 \mathrm{~mm}$ sides and a length of $450 \mathrm{~mm}$.

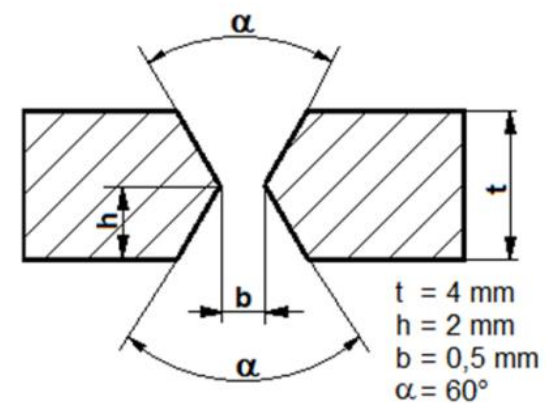

Fig. 2. Preparation of the edges of materials for welding [14]

\section{Research results}

Figure 3 shows the fracture view of the solid sample (L1) after the tensile test. The results obtained from tensile strength tests and tensile curves for a solid sample are presented in table IV and figure 4 . The average value of tensile strength of solid samples was $25.76 \mathrm{MPa}$.

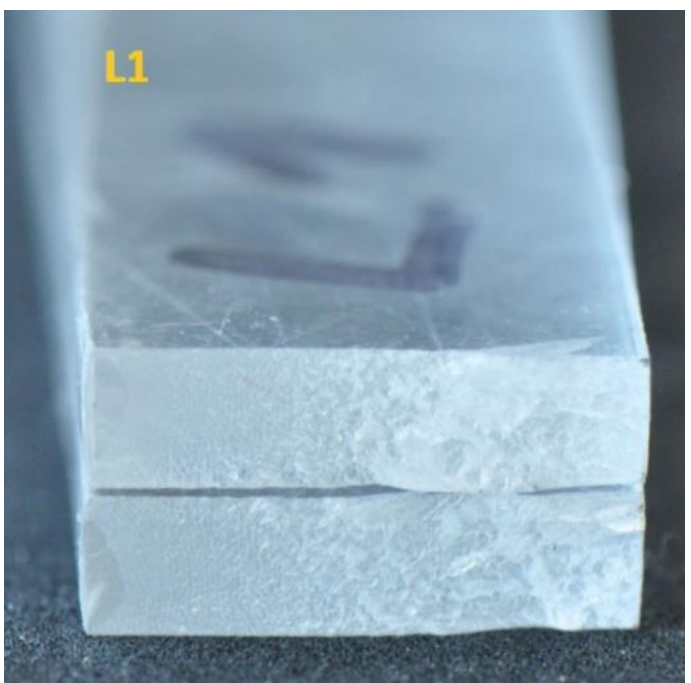

(a)

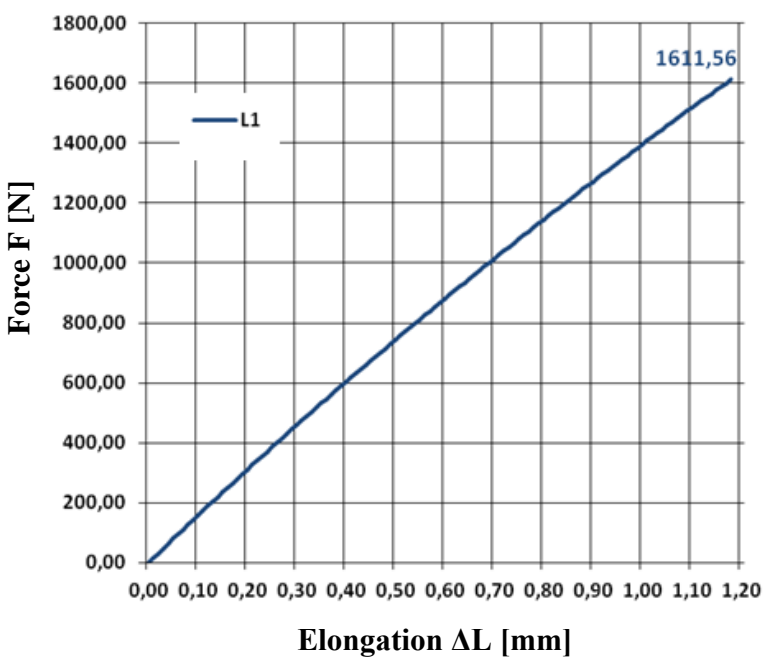

(b)

Fig. 3. a) View of the fracture surfaces after tensile test, b) force-displacement curve of the solid sample

Table IV. Test results of tensile strength of a solid sample: a - sample thickness, b - sample width, A - cross-sectional area of the sample, $\Delta \mathrm{L}$ - elongation, $\mathrm{F}_{\mathrm{r}}$ - maximum force during tension, $\sigma_{\mathrm{r}}$ - tensile strength

\begin{tabular}{cccccccc}
\hline $\begin{array}{c}\text { Sample } \\
\text { designation }\end{array}$ & $\begin{array}{c}\text { Dimensions of the solid } \\
\text { sample } \\
{[\mathbf{m m}]}\end{array}$ & $\begin{array}{c}\mathbf{b} \\
{[\mathbf{m m}]}\end{array}$ & $\begin{array}{c}\mathbf{A} \\
{\left[\mathbf{m m}^{2}\right]}\end{array}$ & $\begin{array}{c}\Delta \mathbf{L} \\
{[\mathbf{m m}]}\end{array}$ & $\begin{array}{c}\mathbf{F r}_{\mathbf{r}} \\
{[\mathbf{N}]}\end{array}$ & $\begin{array}{c}\mathbf{\sigma}_{\mathbf{r}} \\
{[\mathbf{M P a}]}\end{array}$ & $\begin{array}{c}\text { Description of } \\
\text { the sample fractures }\end{array}$ \\
\hline L1 & 4.00 & 15.68 & 62.72 & 1.18 & 1611.56 & 25.69 & brittle fracture \\
L2 & 4.00 & 15.62 & 62.48 & 1.19 & 1609.74 & 25.76 & brittle fracture \\
L3 & 4.00 & 15.63 & 62.52 & 1.17 & 1613.42 & 25.81 & brittle fracture \\
\hline
\end{tabular}

Numerical results obtained from tensile strength tests are presented in table $\mathrm{V}$ for all samples. The stated Ks value is the relative strength of the welded joint compared to the solid sample. An example of the graph of the tensile curve for $\mathrm{T}$ samples is shown in figure 5 . As can be seen from table $\mathrm{V}$, the maximum tensile strength of welded joints was $16.89 \mathrm{MPa}$, which accounted for approximately $65 \%$ of the solid material's tensile strength. 


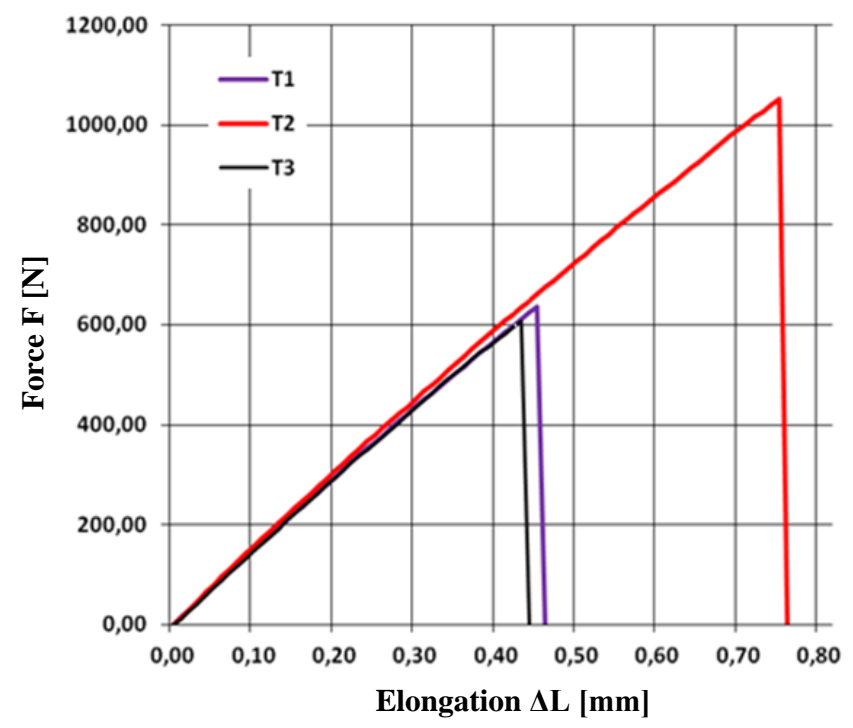

Fig. 5. Characteristics of the tensile test of samples: T1, T2, T3

Table V. Test results of the strength of PMMA welded joints

\begin{tabular}{ccccc}
\hline Sample & $\begin{array}{c}\text { Elongation } \\
\Delta \mathbf{L}[\mathbf{m m}]\end{array}$ & $\begin{array}{c}\text { Force } \\
\mathbf{F}_{\mathbf{w}}[\mathbf{N}]\end{array}$ & $\begin{array}{c}\boldsymbol{\sigma}_{\mathbf{r}} \\
{[\mathbf{M P a}]}\end{array}$ & $\begin{array}{c}\text { Relative strength } \\
\text { of the joint Ks [\%] }\end{array}$ \\
\hline L1 & 1.18 & 1611.56 & 25.76 & - \\
T1 & 0.46 & 635.93 & 10.63 & 41.28 \\
T2* & 0.74 & 1051.16 & 16.89 & 65.56 \\
T3 & 0.44 & 606.66 & 9.75 & 37.86 \\
V1 & 0.31 & 435.50 & 7.03 & 27.30 \\
V2* & 0.74 & 1051.16 & 16.89 & 65.56 \\
V3 & 0.40 & 566.56 & 9.18 & 35.63 \\
P1 & 0.37 & 584.56 & 9.31 & 36.13 \\
P2* & 0.74 & 1051.16 & 16.89 & 65.56 \\
P3 & 0.60 & 865.92 & 13.87 & 53.84 \\
Q1 & 0.38 & 535.51 & 8.77 & 34.06 \\
Q2 & 0.74 & 1051.16 & 16.89 & 65.56 \\
Q3 & 0.49 & 658.34 & 10.91 & 42.34 \\
D1 & 0.35 & 466.44 & 7.76 & 30.14 \\
D2* & 0.74 & 1051.16 & 16.89 & 65.56 \\
D3 & 0.33 & 498.71 & 8.07 & 31.35 \\
K1* & 0.74 & 1051.16 & 16.89 & 65.56 \\
K2 & 0.45 & 633.21 & 10.66 & 41.38 \\
K3 & 0.32 & 458.15 & 7.21 & 27.98 \\
\hline 2 & & &
\end{tabular}

where: $\Delta \mathrm{L}$ - elongation, $\mathrm{F}_{\mathrm{w}}-$ maximum force during tension, $\sigma_{\mathrm{r}}-$ stress,

$\mathrm{K}_{\mathrm{s}}$ - relative strength of the joint, ${ }^{*}$ the same sample

\section{Effect of the temperature}

Welded joints were made for three values of air stream temperature: 330,350 and $370{ }^{\circ} \mathrm{C}$, adopted on the basis of preliminary tests. The resulting welded joints and their fractures after the tensile test (Fig. 6) were subjected to external examination, the purpose of which was to assess the occurrence of welding incompatibilities in the joints.

The data obtained in the conducted tensile test for individual samples were compiled, and the results of tensile strength tests of samples obtained at different heating temperatures are summarized in table V.

The T1 sample has a small HAZ range in the form of gas pores on the surface. A small number of small gas pores appear in the weld. PN-EN13100-1 does not specify detailed requirements related to the visual assessment of the joint (such requirements should be included in the agreed acceptance conditions). The sample was broken in the weld and on the contact surface (lack of side fusion). There are few gas pores visible on the surface of the fracture. The T2 sample shows a larger HAZ (gas pores) range than T1 and small 
pores in the weld. The sample rupture occurred in the weld. The porosities are visible on the fracture surface. Sample T3 has numerous porosities in the weld. The HAZ range is larger than in the T2 sample. The rough face of the weld is visible. Sample rupture occurred in the weld and on the contact surface. Porosities are clearly visible on the fracture surface.
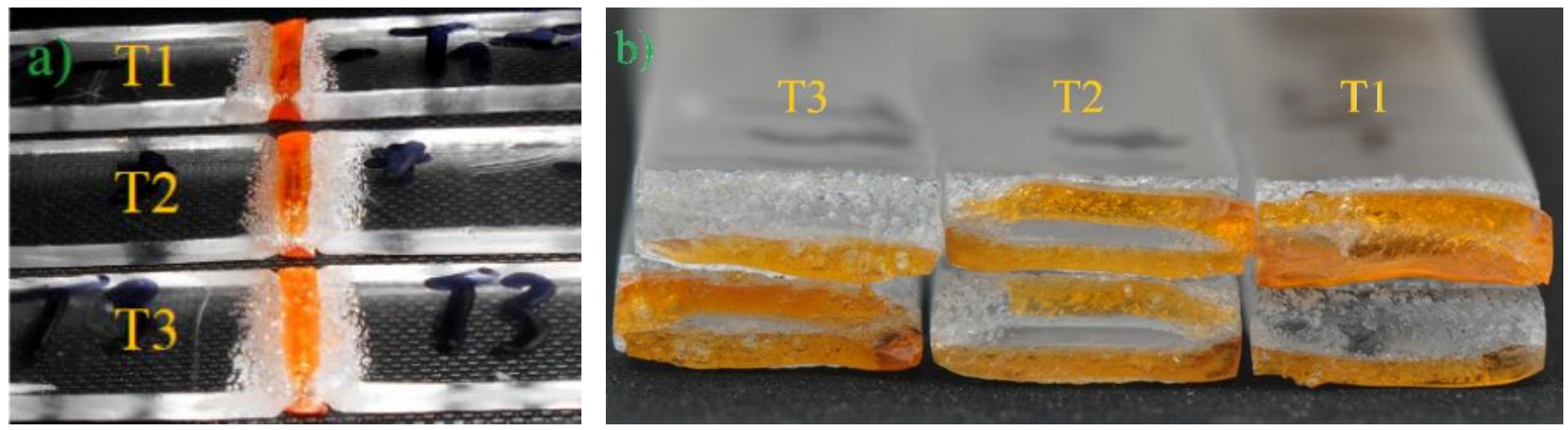

Fig. 6. View of the samples welded at different temperatures: a) welded joints, b) sample fractures after tensile test

The analysis of the data shows that in the case of the first sample (T1), insufficient softening of the welded material was not obtained, hence the resulting lack of side fusion. As the gas (air) temperature increased, the welded plastic became increasingly softened. Joint strength increases, but only up to a point. At higher and higher welding temperatures, the larger and larger gas pores, both in the weld and on the surface of the welding groove, intensified. Porosities are the main reason for the decrease in joint strength (sample T3). Higher welding temperatures cause the plastic to decompose. Its increase of $20{ }^{\circ} \mathrm{C}$ caused a decrease in joint strength by over $25 \%$ (sample T3) compared to sample (T2).

\section{Effect of the welding speed}

Welded joints were made at three welding speeds of 15,30 and $60 \mathrm{~mm} / \mathrm{min}$. The obtained joints and their fractures after a tensile test (Fig. 7) were subjected to external examination. The results of the relative strength tests of tensile samples obtained at different welding speeds are given in table V.

In sample V1, numerous large gas pores are observed in the weld and in the heat affected zone. The weld face is rough and HAZ has a wide reach (up to approx. $8 \mathrm{~mm}$ ). There is no groove filling at the end of the joint. The sample was broken in the weld and on the contact surface. Large gas pores are clearly visible on the fracture surface.
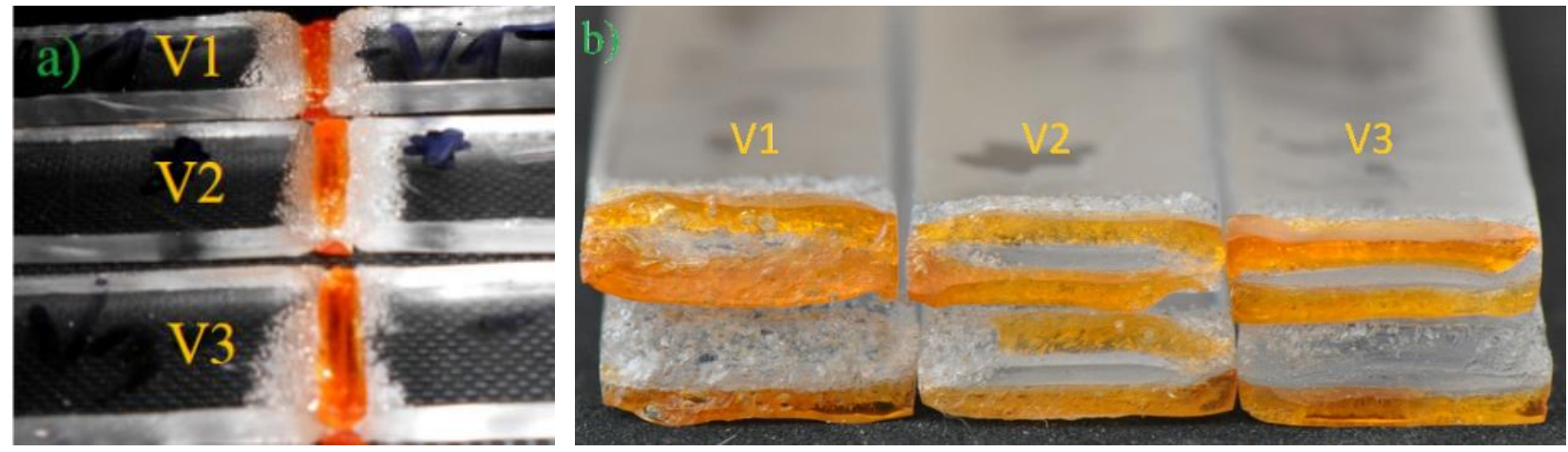

Fig. 7. View of the samples welded at different velocities: a) welded joints, b) sample fractures after tensile test

The V2 sample also shows numerous large gas pores in the weld as well as a rough weld face and a fairly wide heat affected zone (about $5.5 \mathrm{~mm}$ ). There is no groove filling at the end of the joint. The sample was broken in the weld and on the contact surface. Large gas pores are visible on the surface of the fracture. The V3 sample has the smallest HAZ range (approx. $4.5 \mathrm{~mm}$ ) and there are small gas pores. Sample rupture occurred in the weld and on the contact surface (lack of side fusion).

Low welding speed $-15 \mathrm{~mm} / \mathrm{min}$ (sample V1) causes that both in the joint and in the heat affected zone there are numerous and large gas pores, due to too much heat supplied to the sample and the filler rod, which leads to partial destruction of the material. Increasing the welding speed to $30 \mathrm{~mm} / \mathrm{min}$ causes a decrease in the size and number of gas pores, which translates into an increase in the strength of the joint. A further two-fold increase in welding speed (from 30 to $60 \mathrm{~mm} / \mathrm{min}$ ) causes that the amount of heat supplied 
to the sample decreases. PMMA plastic is less and less soften, which makes it difficult to "mix" the polymer chains, and in addition lack of side wall fusion is formed in the joint. The effect of this is a decrease in the strength of the joint. The main causes of low strength in this case are arising lack of side wall fusion and porosity. As the welding speed increases, the aesthetics of the joint increases, but the joint strength decreases.

\section{Effect of the filler rod force}

The welded joints obtained with different filler rod force $(5,10,15 \mathrm{~N})$, and their fractures were subjected to external examination (Fig. 8). The filler rod downforce was determined by reading and counting the indications of the measuring scale on which the welded samples were placed, under the pressure of the filler rod. The results of tensile strength tests of welded samples at different filler rod force are presented in table $\mathrm{V}$.

The P1 sample shows a small HAZ range (approx. $5 \mathrm{~mm}$ ) and small gas pores in the weld. The weld has a slightly convex face. The sample was broken in the weld and on the contact surface.
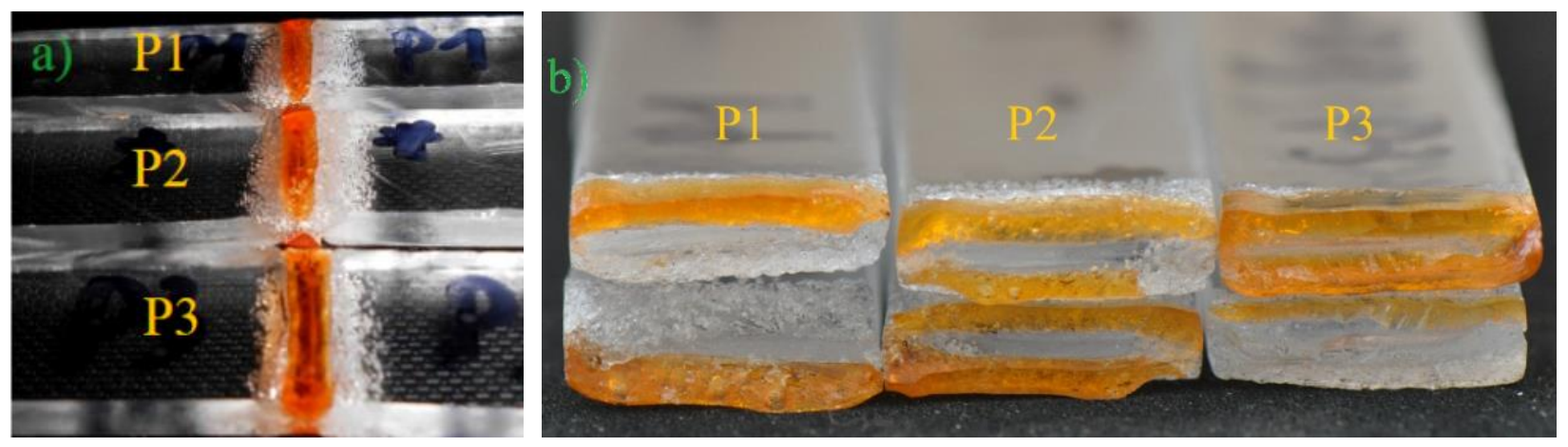

Fig. 8. View of the welded samples subjected to the impact of filler rod downforce: a) welded joints, b) sample fractures after tensile test

Gas pores are visible on the fracture's surface. Sample P2 also has a short range of the heat affected zone $(5.5 \mathrm{~mm})$ and small pores in the weld. The joint was broken in the weld. Gas pores are visible on the fracture's surface. The P3 sample shows a small HAZ range $(3.5 \mathrm{~mm})$ and small gas pores in the weld. From the side of the ridge you can see incomplete filling of the groove (thinning of the weld), and from the opposite side of the convex face of the weld. The sample was broken in the weld and on the contact surface. Porosities are visible on the fracture's surface.

At the pressure of the filler rod with $5 \mathrm{~N}$ force (sample P1), the polymer chains probably did not get close enough to create a permanent and durable joint. As the downforce increases, the strength of the joint increases, but only up to a point. Further increase of the adhesive force to $10 \mathrm{~N}$ (sample P3) causes that the heated welding groove begins to deform. Increased pressure caused that with the bead made from the upper side of the sample, the face of the weld was concave, and from the side of the ridge an overhang was formed. The overhang, as a consequence, reduced the depth of the groove, and after making the bead on the other side, an excess weld was formed. This resulted in a decrease in the weld cross-section that carries the load. However, increasing the downforce also causes the polymer chains to move closer together, which means that despite the reduced weld cross-section, the joint strength is relatively high (approx. $16 \mathrm{MPa}$ ). Further increase of the downforce to $15 \mathrm{~N}$ causes that the weld cross-section decreases and the joint transfers less and less stress.

\section{Effect of the gas flow rate}

Figure 9 shows the welded joints obtained at different gas flow rates $(20,40$ and $60 \mathrm{l} / \mathrm{min})$ and their fractures after a tensile test. The results of tensile strength tests of joints obtained at different heating gas flow rates are presented in table $\mathrm{V}$.

The Q1 sample has a small HAZ range $(2.5 \mathrm{~mm})$ and few gas pores. The joint was broken in the weld and on the contact surface (lack of side fusion in the place marked with an arrow in Fig. 9b). The Q2 sample has a larger HAZ range $(5.5 \mathrm{~mm})$ than the Q1 sample, as well as fine weld gas pores. The joint was broken in the weld. Porosities are visible on the fracture's surface. The Q3 sample shows small, more numerous gas pores in the weld compared to the Q2 joint. Greater concentration of gas pores occurs in the HAZ (width approx. $4.5 \mathrm{~mm}$ ), the face of the weld is quite rough. The sample was broken in the weld and on the contact surface. Porosities are visible on the fracture's surface. 

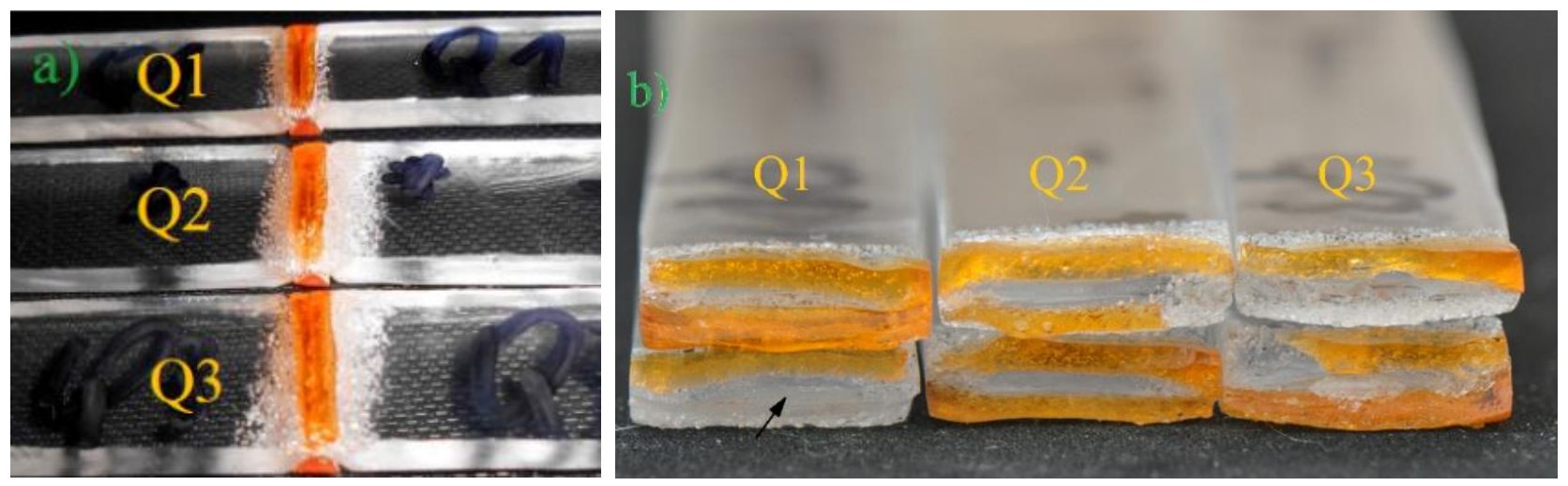

Fig. 9. View of the samples welded with a different air flow rates: a) welded joint, b) sample fractures after tensile test

Low gas flow $(20 \mathrm{l} / \mathrm{min})$ means that the plastic is not softened enough, which results in low strength, on average about $8.7 \mathrm{MPa}$ (lack of side fusion). Increasing the air flow increases the softening of the material and the strength of the joint. Confirmation of this fact is the breaking of the sample in the weld, not on the contact surface (Fig. 9). The increase in strength takes place only up to $40 \mathrm{l} / \mathrm{min}$. Further increase in gas flow (up to $60 \mathrm{l} / \mathrm{min}$ ) causes a decrease in strength. The reason for the decrease in joint strength are, among others, gas pores rising more and more. As the flow of hot air increases, the number of trapped (closed) gas pores between the welded sample and the weld increases. The number of gas pores resulting from the decomposition of the material also increases.

\section{Effect of the nozzle diameter}

Figure 10 shows the joints obtained at different nozzle diameters $(3,5,7 \mathrm{~mm})$ and their fractures after a tensile test.

During welding, it was observed that the smaller the diameter of the nozzle, the more heated air escapes through the side cut-out in the nozzle (Fig. 11). The notch in the nozzle serves to protect the hot air gun from overheating. The results of tensile strength tests of joints obtained for different nozzle diameter are given in table $\mathrm{V}$.
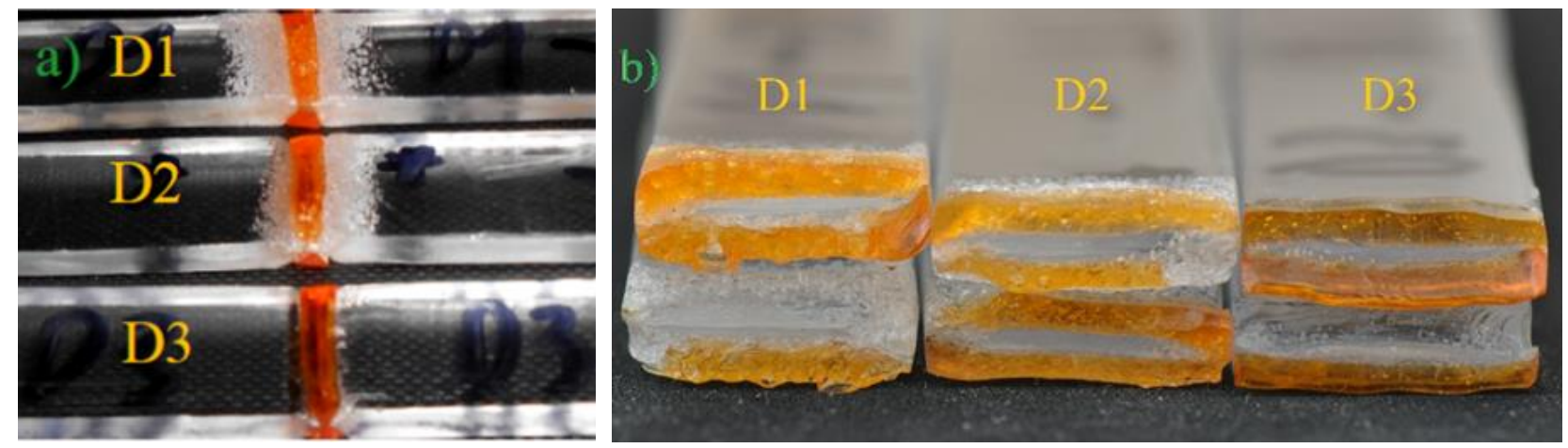

Fig. 10. View of the samples welded with the different nozzle diameters: a) welded joint, b) sample fractures after tensile test

Sample D1 shows a wide range of heat affected zone $(8 \div 8.5 \mathrm{~mm})$ and numerous clusters of gas pores in the weld. The face of the weld is rough. The sample was broken in the weld and on the contact surface. Large gas pores are visible on the surface of the fracture. HAZ has a smaller range (about $5.5 \mathrm{~mm}$ ) on the D2 sample than on the D1 sample. Small pores are visible in the weld. Sample rupture occurs in the weld. Porosities are visible on the fracture's surface. In sample D3 there are no obvious incompatibilities, traces of gas pores are possible. The sample was broken in the weld and on the contact surface (lack of side fusion).

The size of the nozzle diameter affects the amount of heat supplied to the welding area. As the diameter decreases, the softening of the welded material decreases, and the number of porosities formed decreases. This translates into the strength of the joint and the resulting welding defects: porosity and lack of side wall fusion. At a nozzle diameter of $7 \mathrm{~mm}$ (sample D1), a low relative strength of $30 \%$ of the parent material was obtained, which was due to the increased number of porosity present in the joint compared to other samples. With a nozzle diameter of $5 \mathrm{~mm}$ (sample D2), the highest joint strength was obtained. In turn, the small diameter of the nozzle ( $3 \mathrm{~mm}$ in sample D3) causes that the material in the welding area has 
poorly softened and, as a result, lack of side wall fusion has been formed. At this diameter of the nozzle, however, the best joint appearance was obtained. Studies have also shown that the nozzle design itself has a significant impact on the strength of the joint. As the diameter of the nozzle decreases, the amount of heated air escaping through the lateral undercut in the nozzle increases. Limiting the diameter improves the appearance of the weld, and better welding control is also possible.

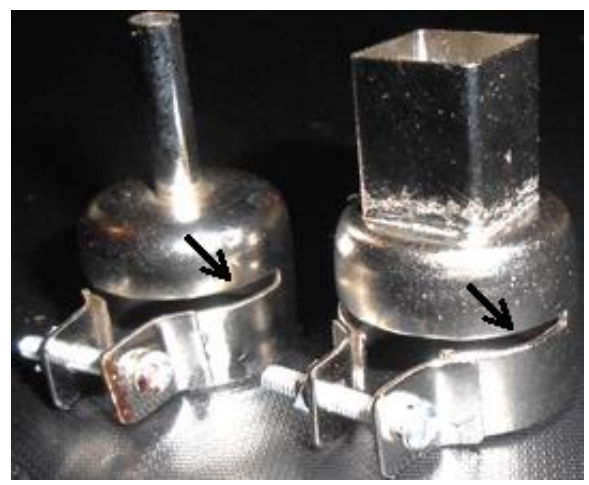

Fig. 11. Picture of the nozzles for welding in a stream of hot air

\section{Effect of the nozzle shape}

Figure 12 shows welded joints made using various shapes of hot air gun nozzles (round, flat, square) and their fractures after a tensile test. When welding with a $10 \times 10$ square nozzle (sample K3), there is a problem with applying adequate pressure $(10 \mathrm{~N})$. The outflow of air stream through the nozzle (larger surface) causes softening of the additional material (filler rod) at a considerable height. The results of tensile strength tests of joints obtained for various nozzle shapes are given in table $\mathrm{V}$.
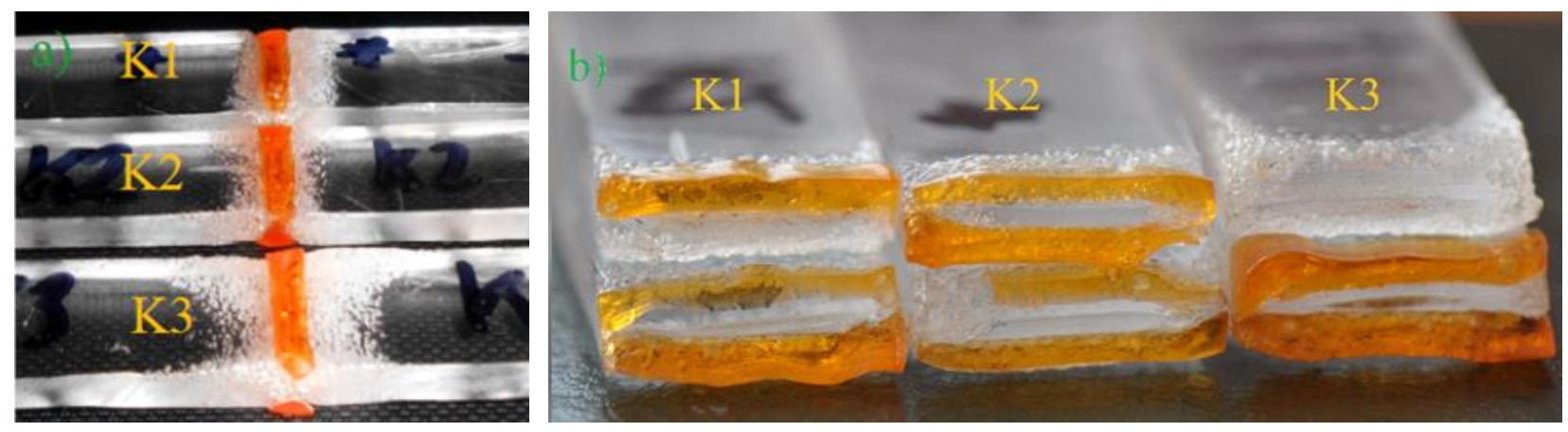

Fig. 12. View of the samples welded with the different nozzle cross-sections: a) welded joint, b) sample fractures after tensile test

The K1 sample shows a small range of heat affected zone (approx. $3 \mathrm{~mm}$ ) and small pores in the weld. The sample was broken in the weld. Porosities are visible on the fracture's surface. The K2 sample also shows a small HAZ range (about $5 \mathrm{~mm}$ ), as well as small gas pores in the weld. Sample rupture occurred in the weld and on the contact surface. Porosities are visible at the fracture. The K3 sample has a wide range of heat affected zone (about $7.5 \mathrm{~mm}$ ) and large, numerous gas pores in the weld. The joint volume increases as well as the rough face of the weld. The sample was broken at the contact surface (lack of side fusion). Porosities are visible on the fracture's surface.

The round nozzle best concentrates most of the heated air within the welding groove. Despite the fact that the flat nozzle has a similar outlet surface as the round nozzle, the joint strength is almost $25 \%$ lower. It is influenced by the width of the nozzle - the wider it is (in relation to the width of the groove), the more heated air escapes outside the area of the welding groove, which causes only partial softening of the welded material in the area of the welding groove and increases the range of heat affected zone. The use of a 10x10 mm square nozzle (sample K3) means that the additional material is softened at a much greater height, which makes it difficult to exert the assumed pressure. The 10x10 square nozzle also causes a lack of adequate softening due to excessive escape of heated air from the sides (no focus in the welding groove) and the obtained strength does not reach the level of 30\% relative strength. The use of this nozzle results in the greatest HAZ reach and the least esthetic weld. The use of a square nozzle, due to the size of the outlet surface, has the greatest impact of heat on the combined sample materials. 


\section{Analysis of the results}

Numerical results obtained from tensile strength tests of all variants of welding parameters for welded joints of polymethyl methacrylate (PMMA) are presented in table V. However, figure 13 presents a graphical comparison of the effect of all analyzed welding parameters of plastic from PMMA on the relative strength of the joint (Ks). As indicated earlier in table V, the set of samples from No. 2 is the same and common for all analyzed test results.

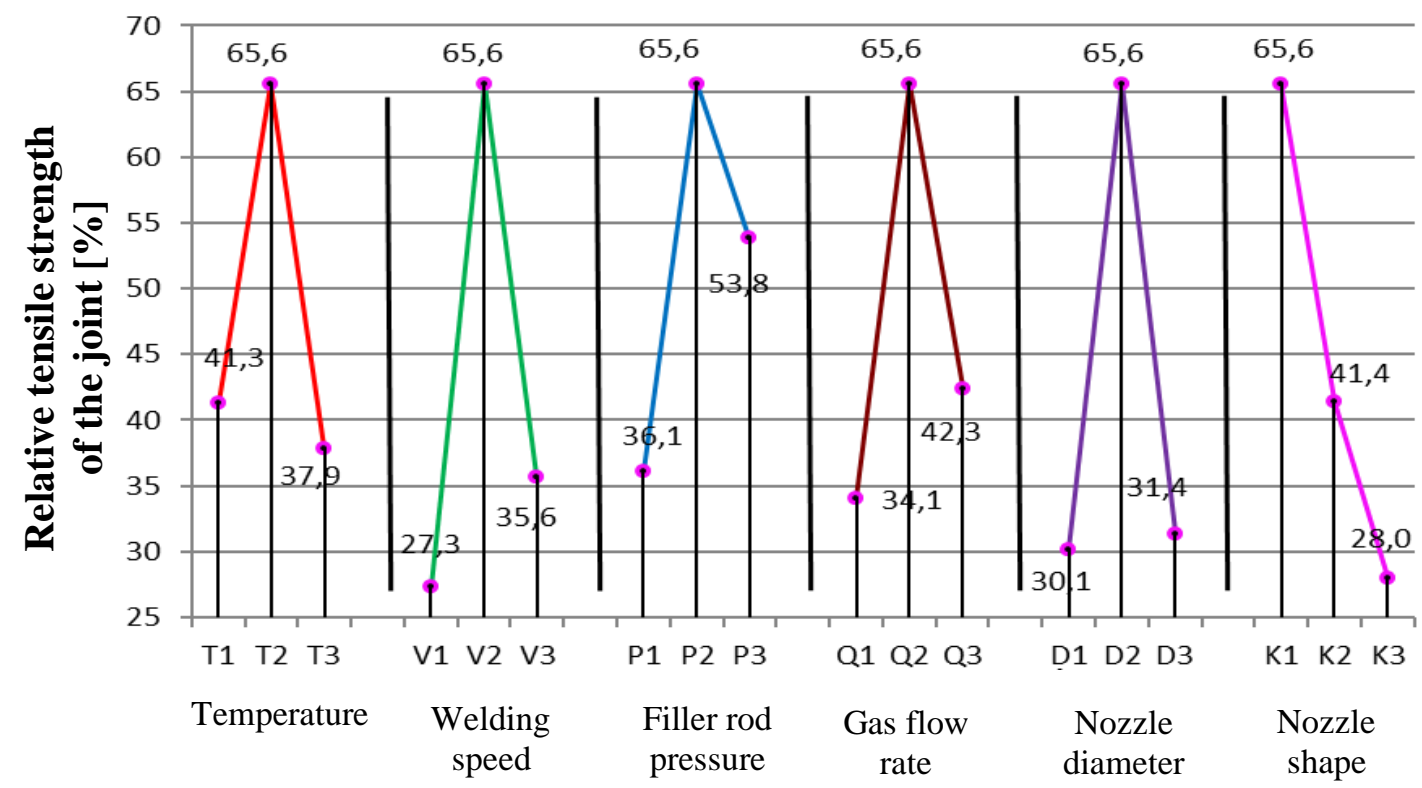

Sample designation

Fig. 13. A summary of the influence of PMMA welding parameters on the relative tensile strength of the joint (Ks)

The analysis shows that in all cases of tested welding parameter combinations it was possible to obtain a joint.

The results of testing the strength of welded joints made of polymethyl methacrylate (PMMA) show that only in two cases of thermoplastic welding parameters summary, the joint strength was obtained at a level greater than $50 \%$ (Fig. 13). The visual assessment of the joints indicates that welding defects occurring in the joints, mainly gas pores and lack of side fusion, have the greatest impact on the achieved strength. The presence of adhesions in most cases disqualifies the suitability of a given joint for operation. At the fractures of the samples, the presence of lack of side wall fusion as well as gas pores of various sizes was visible. The reason for the lack of fusion was too low heat input, insufficient to soften the edge of the welding groove or previously made weld bead. One of the reasons for the lack of fusion may also be the wrong welding technique (one-sided torch tilt). This is visible even in Figure 10a (samples D1, D2), which is also manifested by the uneven coverage of the heat affected zone (HAZ).

Inspection of joints shows that the most common and most easily recognized welding defects were gas pores, both in the weld and on the surface of the joined elements. This was confirmed by visual inspection of the joints as well as after observation of the obtained fracture of the sample. The resulting gas pores have a dual nature. They arise as a result of destruction (decomposition) of the welded material or are the result of "closing" of air particles between the welded elements (native material - weld).

It should be remembered that the amount of heat introduced into the welded elements has the greatest impact on the quality of the joint. It can be controlled, among others by temperature, welding speed, gas flow rate and nozzle designs (size, shape), distance between the nozzle tip and the welded parts.

\section{Summary and Conclusions}

The growing demand for effective and reliable welding methods, as well as requirements related to the increase in the quality and strength of obtained products are the main reason for the development of plastic welding methods. Research conducted in this direction is to certify the suitability of welding processes for welding thermoplastics.

The main purpose of the research was to determine the impact of welding parameters on the strength of welds made of polymethyl methacrylate (PMMA). The research carried out in the work allowed to 
obtain joints which in the majority of the adopted parameters were characterized by medium quality and durability. This was confirmed both during the examination of the samples and in the strength tests carried out. The research shows that the welding parameters used in many cases cause similar defects in the joints, which have a decisive impact on their strength. Lack of side fusion and gas pores were caused by too little or too much heat supplied. The amount of heat input to the welding area is differently affected by other welding parameters.

Certainly, it is possible to achieve greater strength of PMMA welded joints, but this requires more extensive research, with a much larger number of variants and combinations of welding parameters used.

Based on the tests carried out on welded joints of polymethyl methacrylate and analysis of the results obtained, the following conclusions can be drawn:

- Welding incompatibilities have a decisive impact on the strength of welded joints, mainly in the form of lack of side fusion and porosity.

- Porosity was the most common welding defect in the joints.

- No cracks were observed in the heat affected zone.

- The increase in welding temperature increases the strength of the joint until there is no significant distribution of the welded material, which is manifested, among others, in the form of porosity.

- Increasing the welding speed results in an increase in the strength of the joint, even until sufficient softening is achieved.

- When selecting the filler rod's downforce, in addition to the shape and size of the additional material, the type of weld and the bevel of the welding groove should be taken into account.

- When applying more than $10 \mathrm{~N}$ downforce (in relation to the filler rod surface) one-sided welds (beads) should be made.

- Increasing the filler rod force results in a greater number of more similar polymer chains, which with a reduced weld cross-section translates into a relatively high strength of the joint.

- With an increase in hot air flow to $40 \mathrm{l} / \mathrm{min}$. the strength of the joint increases, but only until the softening of the material has a decisive impact on the strength of the joint, and not the resulting porosity.

- As the diameter of the nozzle decreases, the amount of air escaping through the side cut-out in the hotair gun increases and the material becomes less softened.

- An increase in nozzle diameter from 3 to $5 \mathrm{~mm}$ results in an increase in joint strength in a similar way as when testing the effect of temperature and gas flow.

- The smaller the diameter of the nozzle, the easier and more accurately you can control the formation of the weld.

- The round nozzle is most advantageous for concentrating heated air within the welding groove, the larger the nozzle width, the greater the HAZ range and the more difficult the welding process is to control.

- The greatest impact on the joint formation process is the amount of heat supplied to the welding area, which can be controlled by temperature, welding speed, gas flow, nozzle size and shape.

Author Contributions: conceptualization D.P. and D.G.; methodology D.P. and D.G; investigation D.P.; formal analysis D.P. and D.G.; writing, review editing D.G.; supervision D.G.

Funding: The research was funded as part of the scientific statutory work of Warsaw University of Technology.

Conflicts of Interest: The authors declare no conflict of interest.

\section{References}

[1] Ching Y.C., Chuah C.H., Ching K.Y., Abdullah L.C., Rahman A., Applications of thermoplastic-based blends, In book: Recent Developments in Polymer Macro, Micro and Nano Blends, Preparation and Characterisation, Ed. By P.M. Visakh, Gordana Markovic and Daniel Pasquini, Woodhead Publishing, 2017, 111-129. [CrossRef]

[2] National Research Council, Polymer Science and Engineering: The Shifting Research Frontiers, Washington, DC: The National Academies Press, 1994. [CrossRef]

[3] Saechtling H., Polymers. Handbook, WNT, Warszawa 2000.

[4] Szlezyngier W., Polymers, Chemistry, Production technology, Properties, Processing, Application. Vol. 1, FOSZE, Rzeszów 1998.

[5] Peters E.N., Applied Plastics Engineering Handbook (Second Edition), Processing, Materials, and Applications, Plastics Design Library, Second Edition, Edited by Myer Kutz, William Andrew, 2017, 3-26. [CrossRef] 
[6] Gajadhur M., Paper and plastic roughness properties after surface refinement processes, Welding Technology Review 2018, Vol. 90(3), 57-59. [CrossRef]

[7] Ahamad H., Welding of Plastics through Hot Gas Technique: A Review, Global Research and Development Journal for Engineering 2016, Vol. 1(6).

[8] Haque M.S., Siddiqui A., Plastic Welding: Important Facts and Developments, American Journal of Mechanical and Industrial Engineering 2016, Vol. 1(2), 15-19. [CrossRef]

[9] Dodin M.G., Welding Mechanisms of Plastics: A Review, The Journal of Adhesion 1981, 12:2, 99-111. [CrossRef]

[10] Ferenc K., Ferenc J., Welded structures. WNT, Warsaw 2009.

[11] Grewell D., Benatar A., Welding of Plastics: Fundamentals and New Developments, Intern. Polymer Processing XXII (2007) 1, 43-60. [CrossRef]

[12] Pawar E., A Review Article on Acrylic PMMA, IOSR Journal of Mechanical and Civil Engineering 2016, Vol. 13(2), 01-04. [CrossRef]

[13] Ehrenstein Gottfried W., Polymer materials. Structure, properties, application. PWN 2016.

[14] Jasiulek P., Joining plastics by fusion welding, pressure welding, gluing and laminating methods. Wyd. Kabe 2014.

(C) 2019 by the authors. Submitted for possible open access publication under the terms and conditions of the Creative Commons Attribution (CC BY) license (http://creativecommons.org/licenses/by/4.0/). 